\title{
MOV10L1 in piRNA processing and gene silencing of retrotransposons during spermatogenesis
}

\author{
Xiaobin Zhu, Erlei Zhi and Zheng Li \\ Department of Urology, School of Medicine, Ren Ji Hospital, Shanghai Jiao Tong University, 1630 Dongfang Road, \\ Shanghai 200127, China \\ Correspondence should be addressed to Z Li; Email: lizhengboshi@163.com
}

\begin{abstract}
Piwi-interacting RNAs (piRNAs) are a broad group of non-coding small RNAs with important biological functions in germline cells. It is well known that piRNAs can maintain genome integrity via silencing retrotransposons. Previous studies on the animal models harboring gene deletions have shown that the genes involved in piRNA biogenesis and their defective expression can result in the spermatogenic dysfunction. In the past decade, significant progress has been achieved for piRNAs and their roles in male germ cells. This review addresses the advances on piRNAs and piRNA biogenesis-associated genes, with a particular focus on the Moloney leukemia virus 10-like 1 (MOV10L1) gene, whose role in primary piRNA processing and in the 'ping-pong' cycle during secondary piRNA processing has been illustrated. The biological characteristics of piRNA has been summarized, and emphasis was laid on the roles of MOV10L1 in the mediation of piRNA biogenesis and retrotransposons silencing by DNA methylation. Furthermore, the association between MOV10L1 gene polymorphisms and complete maturation arrest in men has been discussed. Hence, thorough literature review was conducted in order to obtain a greater understanding of the function of MOV1OL1 and its mechanisms underlying spermatogenesis in mice and humans.

Free Chinese abstract: A Chinese translation of this abstract is freely available at http://www.reproduction-online.org/content/149/5/ R229/suppl/DC1.

Reproduction (2015) 149 R229-R235
\end{abstract}

\section{Introduction}

Germ cells are highly special cells because they can transmit genetic information across generations. They are set apart from somatic cells during the early stages of embryogenesis. Germline stem cells (GSCs) are the foundation for the generation of haploid gametes, i.e., sperms and oocytes for reproduction. Although it remains controversial whether mammalian females have GSCs, it is well known that GSCs are present in the testes of male mammals to generate sperm throughout their lifespan (Yoshida 2010). In Drosophila, however, germ cells of both sexes are continuously produced in adult gonads (Gilboa \& Lehmann 2004). Gametogenesis from GSCs is regulated precisely by both genetic and epigenetic factors. Approximately, $45 \%$ of the mammalian genome contains transposable elements, and the majority of these elements are retrotransposons. Retrotransposons can be classified into long-terminal repeat (LTR) retrotransposons, nonLTR retrotransposons, e.g., long interspersed element-1 (LINE1), and Alu elements (Jurka et al. 2007). Although transposable elements play a major role in the diversification of transcriptomes, they also pose a potential threat to genome integrity. The P-element-induced wimpy testis (piwi) genes have been shown to be critical for the maintenance of GSCs (Cox et al. 1998).

Piwi-interacting RNAs (piRNAs) are a broad group of 26-31 nt non-coding small RNAs, which are abundantly expressed in animal gonads (Girard et al. 2006). They were first discovered in Drosophila and appeared to serve as an endogenous defense mechanism against transposons by silencing gene expression (Aravin et al. 2003). Most small RNAs have a $5^{\prime}$ monophosphate and $3^{\prime}$ hydroxyl ends, although in some cases, such as in plant siRNAs and microRNAs (miRNAs) or Drosophila siRNAs, the $3^{\prime}$ terminal nucleotide is modified with a 2'-O-methyl marker, which is a universal feature of all piRNAs examined to date (Horwich et al. 2007). A characteristic feature in all piRNAs encountered is the presence of repeat-derived sequences. Intergenic regions and genic transcripts also contribute to the piRNA pool (Aravin \& Bourc'his 2008, Brennecke et al. 2008).

In Drosophila, piRNAs are expressed in both male and female germlines (Lin \& Spradling 1997), whereas they are found to be expressed only in the male gonads in mice (Aravin et al. 2007). The piRNAs that map to retrotransposons have been shown to engage a 
'ping-pong' amplification loop to suppress retrotransposon activity (Gan et al. 2011). Previous reviews (Klattenhoff \& Theurkauf 2008, Yadav \& Kotaja 2014) indicated that piRNAs play an essential role in the maintenance of DNA integrity in germline cells.

\section{Mutations in the piwi genes}

Eukaryotic Argonaute (Ago) proteins can be classified into three different subfamilies, including the Ago, P-element-induced wimpy testis (Piwi), and wormspecific Ago (Wago) (Yigit et al. 2006). The members of the Ago clade are found in almost all organisms, ranging from prokaryotes to eukaryotes. The Ago proteins are ubiquitously expressed and they bind to miRNAs and siRNAs (Meister \& Tuschl 2004). On the other hand, the members of the Piwi clade are found exclusively in animal gonads and they are associated exclusively with piRNAs (Aravin et al. 2006, Girard et al. 2006, Lau et al. 2006, Gunawardane et al. 2007). Ago proteins consist of four domains, i.e., N-terminal, PAZ, MID, and PIWI (Ma et al. 2005, Bamezai et al. 2012).

In Drosophila, Piwi alone is expressed in gonadal somatic cells (Malone et al. 2009). Lin \& Spradling (1997) induced mutations in the piwi gene, and they found that Drosophila individuals with mutations in the piwi gene had a variety of gonadal defects. The ovarioles were found devoid of germline cells, and the mutant testes contained very few bundles of mature sperm without other male germ cells (Lin \& Spradling 1997).

\section{Association between piRNAs and PIWI proteins}

Several studies have reported an association between piRNAs and the Piwi clade of Ago proteins. Aravin et al. (2006) showed that the Piwi family of Ago proteins is essential for germ and stem cell development in invertebrates. In mice, the Piwi clade consists of Miwi2, Mili, and Miwi. Among them, Miwi is expressed in perinatal germ cells. Miwi2 is detected in fetal and perinatal germ cells (Zheng \& Wang 2012), and Miwi is present only in pachytene spermatocytes and round spermatids in the adult testes (Grivna et al. 2006a). Aravin \& Bourc'his (2008) discovered an endogenous piRNA-based defense system that silences retrotransposons in germ cells through a combination of both transcriptional and post-transcriptional mechanisms.

Evidence from previous studies in mice has shown that Mili and Miwi are required for spermatogenesis in mice (Carmell et al. 2007). After mouse PIWI proteins were found to bind to a class of small RNAs, all PIWIassociated small RNAs, including repeat-associated siRNAs (rasiRNAs), were designated as piRNAs. The silencing of transposable elements has been considered to occur by the de novo DNA methylation of their regulatory regions (Aravin et al. 2006).

\section{Mutations in the piRNA pathway genes lead to germline-specific defects}

The Piwi genes and the piRNA biogenesis-associated genes have been shown to be expressed at various stages of germ cell development in the testis (Pillai \& Chuma 2012). In mouse, PIWI proteins are expressed throughout spermatogenesis, MIWI2 was detected only in embryonic stages (Aravin \& Bourc'his 2008), while MILI was reported to localize in all stages but to be enriched in spermatocytes and MIWI was found from meiotic pachytene germ cells (Deng \& Lin 2002, KuramochiMiyagawa et al. 2004). Moloney leukemia virus 10-like 1 (MOV10L1) was clearly expressed in pachytene spermatocytes but absent in post-meiotic spermatids (Frost et al. 2010). Shoji et al. (2009) detected that Tudordomain-related protein 9 (TDRD9) was expressed in mitotic spermatogonia, meiotic spermatocytes, haploid spermatids in the mouse testis. By immunofluorescence, MAEL was found to be expressed in spermatocytes and round spermatids (Soper et al. 2008) and MVH was detected to be expressed in the male germ cells from E10.5 to around spermatid (Kuramochi-Miyagawa et al. 2010). Just like most members of the TDRD family, Tdrd12 was found to play an essential role for spermatogenesis and to be expressed in meiotic spermatocytes, postmeiotic round spermatids, and elongating spermatids in mouse testis (Pandey et al. 2013). Studies on animals that harbor these genes' deletions have consistently shown that the defective expression of one or more of the genes associated with the piRNA pathway result in the development of infertility.

Recently, Miwi has been found to be exclusively expressed in mouse testes and essential for spermatogenesis (Deng \& Lin 2002). Aravin \& Bourc'his (2008) reported that a mutation in the Mili and Miwi2 genes led to the elimination of transposable elements in DNA methylation and sterility in male rats. Another Piwi pathway gene, namely Mael, was found to be vital for the correct differentiation of GSC in Drosophila and vertebrates (Pek et al. 2009). It has been indicated that Miwi and Mili were both essential for the meiotic process and play a significant role in controlling transposons in the male germline (KuramochiMiyagawa et al. 2008). Similar to the case observed in flies, mutations in the Miwi2 gene resulted in the accumulation of DNA damage (Carmell et al. 2007). Kuramochi-Miyagawa et al. (2004) conducted a study on Mili-deficient mice and found that Mili played an important part in the timing of this de novo methylation of the LINE1 and IAP regulatory regions. Houwing et al. studied the Piwi pathway proteins Ziwi and Zili in zebrafish. In their study, Zili was found to be present with subcellular localization at all stages during germ cell differentiation and has a dynamic distribution in the nucleus and cytoplasm. Both Zili and Ziwi were found 
to bind to piRNA populations. Zili played a vital role in meiosis, and eggs of female zebrafish with mutations in the zili gene displayed defects in the meiotic process. Interestingly, zili ${ }^{-/}$germ cells did not undergo female development, and $z i l i^{-1}$ fish are always phenotypically male (Houwing et al. 2008). To date, however, the molecular mechanisms that underlie piRNA-induced DNA methylation remain to be elucidated. Piwi-piRNA complexes are localized in the nucleus, and piRNA protein has been found to be localized in the nucleus in Drosophila (Brennecke et al. 2007), reflects a potential role of piRNA proteins in the regulation of DNA transcription and cell cycle progression.

\section{Genes involved in piRNA generation}

Numerous genes are involved in the generation of piRNAs. In particular, Piwi proteins are required for their biogenesis and function. Piwi proteins interact with armitage (armi) and zucchini (zuc) in Drosophila to regulate piRNA biogenesis (Olivieri et al. 2010, Saito et al. 2010). In addition, genes such as mov10, Spindle-E (spn-E), and Maelstrome (mael) have been implicated in the biogenesis of piRNAs (Meister et al. 2005, Soper et al. 2008, Patil \& Kai 2010). The depletions of Piwi, Zuc, and Arm levels in the cells have been found to reduce the piRNA levels. There are two piRNA biogenesis pathways, known as the primary processing pathway and the ping-pong amplification cycle, as we illustrated in Fig. 1. Tudor-domain-containing proteins or TDRDs have been increasingly studied in relationship

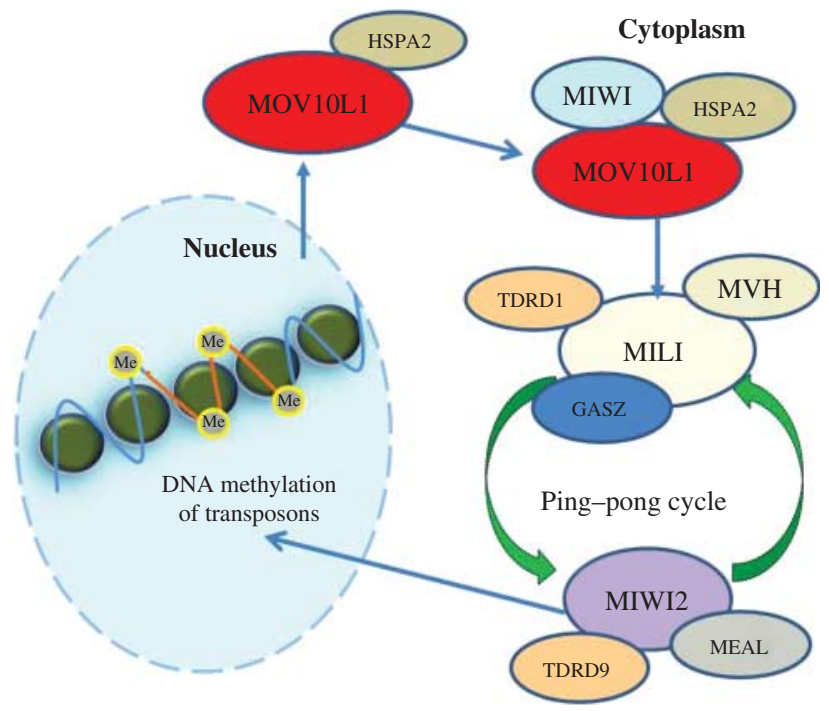

Figure $1 \mathrm{~A}$ model for the role of MOV10. HSPA2 couples with MOV10L1 and then MOV10L1 interacts with PIWI protein (MILI), which can help pre-piRNAs load onto a PIWI protein. After pre-piRNAs associating with a PIWI protein (MILI), target RNAs are cleaved to generate secondary piRNAs. MIWI2, TDRD9, and MEAL act together and generate pi-body components. PiRNA-bound MIWI2 enters nucleus to regulate DNA methylation of transposon loci. The green circular arrows indicate intra-Piwi ping-pong. with Piwi proteins (Chen et al. 2009). These proteins belong to the Tudor protein family and have also been found to play a key role in piRNA biogenesis.

\section{Generation of piRNAs}

Two pathways have been proposed for the generation of piRNAs. In the first pathway, termed the primary pathway, antisense piRNA precursor transcripts are processed by Zuc, a putative endonuclease (Nishimasu et al. 2012). The resulting products have an $U$ at the first nucleotide position, and are loaded on Piwi or Aub (Klattenhoff \& Theurkauf 2008). The $3^{\prime}$ end of this product is then trimmed and methylated to obtain mature piRNAs (Brennecke et al. 2007). On the whole, piRNAs tend to have a very strong sequence bias toward Uridine (77.6\%) at their $5^{\prime}$ end (Grivna et al. 2006b), which suggests that they may be generated by Dicer-like cleavage. As Dicer produces 21- to 22-nt products from double-stranded precursors and the length of the piRNAs ranges from 26 to $31 \mathrm{nt}$, they may be produced via a Dicer-independent mechanism (Klattenhoff \& Theurkauf 2008).

In the second pathway, namely the 'ping-pong' pathway, Ago3 binds to sense-strand piRNAs, which catalyzes the cleavage of the antisense strand at an A:U base pair. This in turn leads to the generation of the $5^{\prime}$ end of antisense piRNA. The $5^{\prime}$ ends of the resulting cleavage products are then loaded on to Aub or Piwi, and trimmed and methylated at the $3^{\prime}$ end to yield the mature antisense piRNA. Piwi-antisense piRNA complexes enter the nucleus, thus silencing gene expression and producing sense-strand piRNAs and antisense strand piRNA precursors that exported from the nucleus to nuage. The mature antisense piRNA-Ago3 complexes are then proposed to bind to and cleave sense-strand RNAs (Brennecke et al. 2007, Klattenhoff \& Theurkauf 2008). A model for ping-pong cycle is shown in Fig. 2.

\section{Role of Mov10l1}

The armitage gene encodes a homolog of SDE3, an RNA helicase that is involved in RNAi in Arabidopsis (Tomari et al. 2004). A previous study showed that the putative RNA helicase encoded by armitage is vital for the Piwi function in Drosophila (Malone et al. 2009). Mice and humans have two genes that are analogous to the armitage gene of Drosophila, namely MOV10 and MOV10L1 in human (Wang et al. 2001, Zheng et al. 2010). Frost et al. analyzed the expression levels of these two genes in mouse testis postnatally during the development of the first spermatogenic waves. The expression pattern of Mov10l1 was found to be similar to that of Mili, another murine Piwi gene that has been found vital for piRNA synthesis and function. The study in a mice model has demonstrated that there were 


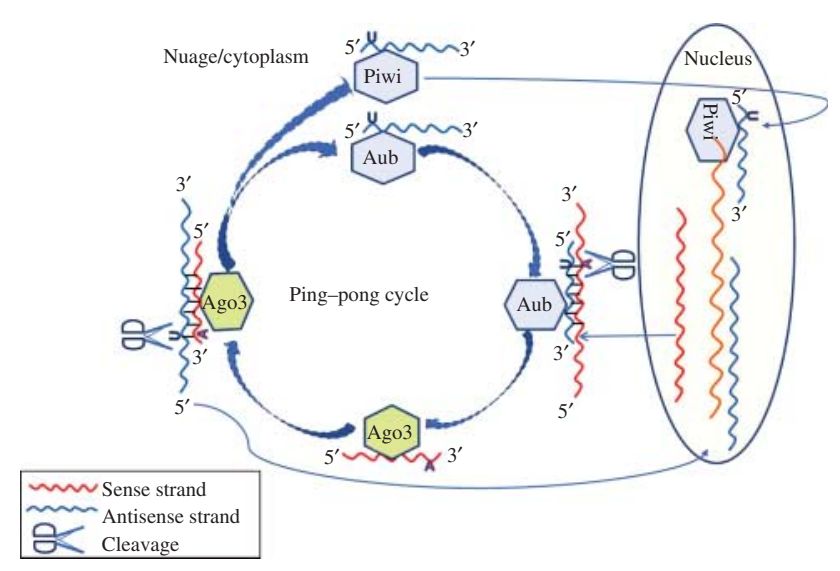

Figure 2 A model for ping-pong cycle. Ago3 binds to sense-strand piRNAs and produces Ago3-piRNA complexes, which cleave the antisense-strand transcript precursors, producing antisense-strand piRNAs. PIWI and Aub bind to antisense-strand piRNAs and generate Piwi-antisense piRNA complexes and Aub-antisense-strand piRNA complexes. Aub-antisense-strand piRNA complexes target the cleavage of sense transcripts, producing the sense-strand piRNAs that load onto Ago3. Piwi-antisense piRNA complexes enter the nucleus, which results in silencing gene expression and producing sense-strand piRNAs and antisense-strand piRNA precursors.

associations between Mov10l1 and Mili, Miwi, and Miwi2 (Frost et al. 2010). The Mili and Miwi genes are important for the synthesis of piRNAs, as evidenced by the knockdown mutations in these genes, which result in the inhibition of piRNA synthesis (Kuramochi-Miyagawa et al. 2004). Moreover, purification of MOV10L1 has revealed the presence of piRNA (Zheng et al. 2010).

Liu et al. (2001) revealed that the putative RNA helicase encoded by differently sized transcripts in testis (exons 1-26) and heart (exons 15-26). The testis-specific isoform has also been referred to as MOV10L1 (Meister et al. 2005), which has been identified to be expressed in the germ cells in mice (Zheng et al. 2010). This gene encodes a putative RNA helicase; however, little is known about this helicase and its function. The $\mathrm{N}$-terminal portion of MOV10L1 is not homologous to that in any other mouse proteins, and the C-terminal RNA helicase region of this protein exhibits very low levels of homology (45\% amino acid identity) with MOV10. Mov10l1 was found to be primarily expressed in pachytene spermatocytes. To generate Mov10/1 ${ }^{-/}$ mice, the exon that encoded the putative helicase domain was flanked by LoxP sites, and a global deletion of Mov10l1 was achieved by breeding Mov $10 / 1^{+/ f l}$ mice to CAG-Cre transgenic mice. Using these mutant mice, Frost et al. (2010) discovered that Mov10/1 was essential for the piRNA-dependent repression of retrotransposons. Male mice with the Mov $10 / 1^{-1-}$ genotype were sterile due to the defective role of this protein in meiosis, both MILI and TDRD1 were found to be expressed in spermatogonia but not in spermatocytes in Mov10/1 ${ }^{-/-}$ testis, thus leading to a sharp reduction in testicle size and weight. Female mice with the same genotype exhibited normal fertility. This suggests that the Mov10/1 gene is vital for fertility in male mice (Zheng et al. 2010). To date, not any correlation studies can explain that the Mov $10 / 1^{-/-}$mice is still fertile.

In female mice, TAF4B is a gonad-enriched subunit of the TFIID complex required for fertility (Voronina et al. 2007). Lovasco et al. reported the development of premature reproductive senescence in young Taf $4 b$ null female mice. In brief, they evaluated the levels of gene expression in these mice in comparison with WT controls. Interestingly, Mov10/1 was found to be expressed in mouse oocytes, and their expression levels were significantly reduced in the Taf $4 b$-null mouse (Lovasco et al. 2010). Although the Mov10/1-/-; mutants contained the reduced transcription levels of the MILI protein, they also lacked piRNAs binding to this protein. In other words, Mov10l1 was found to be indirectly associated with piRNAs and play a major role in the process of piRNA biogenesis by interacting with the above-mentioned PIWI proteins (Zheng et al. 2010). The importance of MOV1OL1 has been documented in patients at risk of azoospermia. In the group of cryptorchid boys at high risk of infertility, the expression of DDX4, MAEL, MOV1OL1, PIWIL2, PIWIL4, and TDRD9 was impaired, which indicated that gene instability induced by impaired expression of transposon silencing genes contribute to the development of azoospermia (Hadziselimovic et al. 2011). The MOV10L1 gene is thus named because it is homologous to MOV10. The effect of Mov10/1 inactivation on two retrotransposons, LINE1 and IAP, were shown in mice testes. In brief, both LINE1 and IAP transcripts increased dramatically in Mov $10 / 1^{-1-}$ testes (Zheng et al. 2010).

Apart from the Mov10/1 transcript, two smaller transcripts, namely Champ and Csm, have been described previously. Liu et al. reported a novel MEF2C-dependent gene that encodes a cardiacrestricted protein. This gene, designated Champ (for cardiac helicase activated by MEF2 protein), contained seven conserved motifs which are characteristic of helicases involved in RNA processing, DNA replication, and transcription. Champ plays a role in a cardiacspecific regulatory pathway for RNA processing and/or transcriptional control (Liu et al. 2001). Ueyama et al. discovered a Mov10l1 isoform that encodes a putative RNA helicase, which was downregulated in the hearts of Nkx2.5-null mice embryos. This gene was designated Csm (for cardiac-specific isoform of Mov10/1), and it was found to be identical to the 3 ' region of the Mov10/1 gene (Ueyama et al. 2003). Thus, as outlined in the previous section, a considerable body of evidence indicates that MOV10L1 is vital for the generation of piRNAs. A previous study has investigated the association between MOV10L1 and male infertility in humans. Sarkardeh et al. conducted a PCR single-strand conformation polymorphism (PCR-SSCP) study on 30 infertile men with complete maturation arrest in their 
spermatocyte levels. Their results suggest that MOV10L1 gene polymorphisms may be linked to infertility in men with complete maturation arrest (Sarkardeh et al. 2014).

Thus far, the function of Piwi-piRNA complexes has not been fully elucidated. However, some studies on the complexes have suggested that they may play a role in the epigenetic regulation of transposable elements in GSCs (Brennecke et al. 2008, Kuramochi-Miyagawa et al. 2008). Deep sequencing of piRNA libraries led to the revelation that piRNAs have a very complex nature of sequences, corresponding to several million individual piRNA clusters as opposed to miRNA clusters, which are numbered in the hundreds (Grivna et al. 2006b, Aravin \& Bourc'his 2008). Lee et al. (2011) previously reported the presence of piRNAs in the mice neurons. In another study, neuronally expressed piRNAs were subjected to deep sequencing and validation by Northern blotting. In that study, a total of 372 distinct piRNA clusters were identified from the CNS tissue of Aplysia californica (Rajasethupathy et al. 2012). Serotonin exposure increased the methylation of Cpg islands in the CREB2 promoter, which leads to long-term downregulation of the CREB2 RNA and protein levels. They studied the regulatory role of these piRNAs in this memory-related synaptic plasticity by determining changes in the expression levels of these piRNAs followed by serotonin exposure. Interestingly, their findings revealed that PiwipiRNA complexes actively demethylated the CREB2 promoter region in A. californica neurons.

\section{Summary}

The piRNAs have a wide range of functionality and are not always easy to identify; therefore, they have not been thoroughly studied beyond their functions in germ cells. Numerous studies have found the associations between piRNA biogenesis genes and fertility; however, the exact mechanism of action of Piwi-piRNA complexes remains to be elucidated. Moreover, the mechanism of piRNAassociated gene silencing also remains to be determined. Overall, based on all the reviewed studies, it has been well established that MOV10L1 is vital for the generation of piRNAs and spermatogenesis. As mentioned previously, some studies on humans have also reported an association between MOV1OL1 gene polymorphisms and infertility (Sarkardeh et al. 2014). This may indicate that the MOV1OL1 gene mutations with loss-of-function may cause male infertility in human. Although Mov10/1 is also expressed as a cardiac-specific isoform in the heart and plays a role in a cardiac-specific regulatory pathway for piRNA processing and/or transcriptional control, full-length Mov10/1 seems to be specifically found in the mouse male germline and Mov10/1 ${ }^{-1-}$ mice impaired only spermatogenesis as we referred to above (Frost et al. 2010). Studies in mice have identified the presence of piRNAs in neurons and play a role in spine morphogenesis (Lee et al. 2011). Thus, on the basis of the reviewed evidence, it can be proposed that piRNAs play much broader roles than it have been previously appreciated. A study by Hadziselimovic et al. (2011) reported the lack of expression of MOV1OL1 in cryptorchid boys at high risk of developing azoospermia. The lower level of testosterone and free-androgen was observed in cryptorchid infants, indicating insufficient gonadotropin and testosterone stimulation (Pierik et al. 2009). Thus, mutations in the MOV1OL1 gene may be linked to low gonadotropin levels in humans. Although there are interesting hints supporting it, further studies still need to be confirmed on molecular details of MOV10L1 gene's function in hormone secretion. Therefore, several questions remain to be answered before MOV1OL 1 obtain a greater insight into its function, and we also believed that more and more researchers will dedicate to the study of MOV1OL1 and other piRNAassociated genes functions.

\section{Declaration of interest}

The authors declare that there is no conflict of interest that could be perceived as prejudicing the impartiality of the review.

\section{Funding}

This study was supported by a key grant from National Nature Science Foundation of China (grant number 31230048), Shanghai Hospital Development Center (grant number SHDC12014236), and the Key Discipline and Specialty Foundation of Shanghai Municipal Commission of Health and Family Planning, and Shanghai Pujiang Program (11PJ1406400).

\section{Acknowledgements}

We thank Prof. Feng Zhang for critical comments.

\section{References}

Aravin AA \& Bourc'his D 2008 Small RNA guides for de novo DNA methylation in mammalian germ cells. Genes and Development 22 970-975. (doi:10.1101/gad.1669408)

Aravin AA, Lagos-Quintana M, Yalcin A, Zavolan M, Marks D, Snyder B, Gaasterland T, Meyer J \& Tuschl T 2003 The small RNA profile during Drosophila melanogaster development. Developmental Cell 5 337-350. (doi:10.1016/S1534-5807(03)00228-4)

Aravin A, Gaidatzis D, Pfeffer S, Lagos-Quintana M, Landgraf P, lovino N, Morris P, Brownstein MJ, Kuramochi-Miyagawa S, Nakano T et al. 2006 A novel class of small RNAs bind to MILI protein in mouse testes. Nature 442 203-207. (doi:10.1038/nature04916)

Aravin AA, Hannon GJ \& Brennecke J 2007 The Piwi-piRNA pathway provides an adaptive defense in the transposon arms race. Science $\mathbf{3 1 8}$ 761-764. (doi:10.1126/science.1146484)

Bamezai S, Rawat VP \& Buske C 2012 Concise Review: The Piwi-piRNA axis: pivotal beyond transposon silencing. Stem Cells 30 2603-2611. (doi:10.1002/stem.1237) 
Brennecke J, Aravin AA, Stark A, Dus M, Kellis M, Sachidanandam R \& Hannon GJ 2007 Discrete small RNA-generating loci as master regulators of transposon activity in Drosophila. Cell 128 1089-1103. (doi:10.1016/j.cell.2007.01.043)

Brennecke J, Malone CD, Aravin AA, Sachidanandam R, Stark A \& Hannon GJ 2008 An epigenetic role for maternally inherited piRNAs in transposon silencing. Science 322 1387-1392. (doi:10.1126/science. 1165171)

Carmell MA, Girard A, van de Kant HJ, Bourc'his D, Bestor TH, de Rooij DG \& Hannon GJ 2007 MIWI2 is essential for spermatogenesis and repression of transposons in the mouse male germline. Developmental Cell 12 503-514. (doi:10.1016/j.devcel.2007.03.001)

Chen C, Jin J, James DA, Adams-Cioaba MA, Park JG, Guo Y, Tenaglia E, Xu C, Gish G, Min J et al. 2009 Mouse Piwi interactome identifies binding mechanism of Tdrkh Tudor domain to arginine methylated Miwi. PNAS 106 20336-20341. (doi:10.1073/pnas.0911640106)

Cox DN, Chao A, Baker J, Chang L, Qiao D \& Lin H 1998 A novel class of evolutionarily conserved genes defined by piwi are essential for stem cell self-renewal. Genes and Development 12 3715-3727. (doi:10.1101/ gad.12.23.3715)

Deng W \& Lin H 2002 miwi, a murine homolog of piwi, encodes a cytoplasmic protein essential for spermatogenesis. Developmental Cell 2 819-830. (doi:10.1016/S1534-5807(02)00165-X)

Frost RJ, Hamra FK, Richardson JA, Qi X, Bassel-Duby R \& Olson EN 2010 MOV10L1 is necessary for protection of spermatocytes against retrotransposons by Piwi-interacting RNAs. PNAS 107 11847-11852. (doi:10. 1073/pnas.1007158107)

Gan H, Lin X, Zhang Z, Zhang W, Liao S, Wang L \& Han C 2011 piRNA profiling during specific stages of mouse spermatogenesis. RNA 17 1191-1203. (doi:10.1261/rna.2648411)

Gilboa L \& Lehmann R 2004 How different is Venus from Mars? The genetics of germ-line stem cells in Drosophila females and males Development 131 4895-4905. (doi:10.1242/dev.01373)

Girard A, Sachidanandam R, Hannon GJ \& Carmell MA 2006 A germlinespecific class of small RNAs binds mammalian Piwi proteins. Nature $\mathbf{4 4 2}$ 199-202. (doi:10.1038/nature04917)

Grivna ST, Pyhtila B \& Lin H 2006a MIWI associates with translational machinery and PIWI-interacting RNAs (piRNAs) in regulating spermatogenesis. PNAS 103 13415-13420. (doi:10.1073/pnas.0605506103)

Grivna ST, Beyret E, Wang Z \& Lin H 2006b A novel class of small RNAs in mouse spermatogenic cells. Genes and Development 20 1709-1714. (doi:10.1101/gad.1434406)

Gunawardane LS, Saito K, Nishida KM, Miyoshi K, Kawamura Y, Nagami T, Siomi H \& Siomi MC 2007 A slicer-mediated mechanism for repeatassociated siRNA $5^{\prime}$ end formation in Drosophila. Science 315 1587-1590. (doi:10.1126/science.1140494)

Hadziselimovic F, Hadziselimovic NO, Demougin P, Krey G \& Oakeley EJ 2011 Deficient expression of genes involved in the endogenous defense system against transposons in cryptorchid boys with impaired minipuberty. Sexual Development: Genetics, Molecular Biology, Evolution, Endocrinology, Embryology, and Pathology of Sex Determination and Differentiation 5 287-293. (doi:10.1159/000335188)

Horwich MD, Li C, Matranga C, Vagin V, Farley G, Wang P \& Zamore PD 2007 The Drosophila RNA methyltransferase, DmHen1, modifies germline piRNAs and single-stranded siRNAs in RISC. Current Biology 17 1265-1272. (doi:10.1016/j.cub.2007.06.030)

Houwing S, Berezikov E \& Ketting RF 2008 Zili is required for germ cell differentiation and meiosis in zebrafish. EMBO Journal 27 2702-2711. (doi:10.1038/emboj.2008.204)

Jurka J, Kapitonov VV, Kohany O \& Jurka MV 2007 Repetitive sequences in complex genomes: structure and evolution. Annual Review of Genomics and Human Genetics 8 241-259. (doi:10.1146/annurev.genom.8. 080706.092416)

Klattenhoff C \& Theurkauf W 2008 Biogenesis and germline functions of piRNAs. Development 135 3-9. (doi:10.1242/dev.006486)

Kuramochi-Miyagawa S, Kimura T, Ijiri TW, Isobe T, Asada N, Fujita $Y$, Ikawa M, Iwai N, Okabe M, Deng W et al. 2004 Mili, a mammalian member of piwi family gene, is essential for spermatogenesis. Development 131 839-849. (doi:10.1242/dev.00973)

Kuramochi-Miyagawa S, Watanabe T, Gotoh K, Totoki Y, Toyoda A, Ikawa M, Asada N, Kojima K, Yamaguchi Y, ljiri TW et al. 2008 DNA methylation of retrotransposon genes is regulated by Piwi family members MILI and MIWI2 in murine fetal testes. Genes and Development 22 908-917. (doi:10.1101/gad.1640708)

Kuramochi-Miyagawa S, Watanabe T, Gotoh K, Takamatsu K, Chuma S, Kojima-Kita K, Shiromoto Y, Asada N, Toyoda A, Fujiyama A et al. 2010 $\mathrm{MVH}$ in piRNA processing and gene silencing of retrotransposons. Genes and Development 24 887-892. (doi:10.1101/gad.1902110)

Lau NC, Seto AG, Kim J, Kuramochi-Miyagawa S, Nakano T, Bartel DP \& Kingston RE 2006 Characterization of the piRNA complex from rat testes. Science 313 363-367. (doi:10.1126/science.1130164)

Lee EJ, Banerjee S, Zhou H, Jammalamadaka A, Arcila M, Manjunath BS \& Kosik KS 2011 Identification of piRNAs in the central nervous system. RNA 17 1090-1099. (doi:10.1261/rna.2565011)

Lin H \& Spradling AC 1997 A novel group of pumilio mutations affects the asymmetric division of germline stem cells in the Drosophila ovary. Development 124 2463-2476.

Liu ZP, Nakagawa O, Nakagawa M, Yanagisawa $H$, Passier $R$, Richardson JA, Srivastava D \& Olson EN 2001 CHAMP, a novel cardiac-specific helicase regulated by MEF2C. Developmental Biology 234 497-509. (doi:10.1006/dbio.2001.0277)

Lovasco LA, Seymour KA, Zafra K, O'Brien CW, Schorl C \& Freiman RN 2010 Accelerated ovarian aging in the absence of the transcription regulator TAF4B in mice. Biology of Reproduction 82 23-34. (doi:10. 1095/biolreprod.109.077495)

Ma JB, Yuan YR, Meister G, Pei Y, Tuschl T \& Patel DJ 2005 Structural basis for $5^{\prime}$-end-specific recognition of guide RNA by the A. fulgidus Piwi protein. Nature 434 666-670. (doi:10.1038/nature03514)

Malone CD, Brennecke J, Dus M, Stark A, McCombie WR, Sachidanandam R \& Hannon GJ 2009 Specialized piRNA pathways act in germline and somatic tissues of the Drosophila ovary. Cell 137 522-535. (doi:10.1016/j.cell.2009.03.040)

Meister G \& Tuschl T 2004 Mechanisms of gene silencing by doublestranded RNA. Nature 431 343-349. (doi:10.1038/nature02873)

Meister G, Landthaler M, Peters L, Chen PY, Urlaub H, Luhrmann R \& Tuschl T 2005 Identification of novel argonaute-associated proteins. Current Biology 15 2149-2155. (doi:10.1016/j.cub.2005.10.048)

Nishimasu H, Ishizu H, Saito K, Fukuhara S, Kamatani MK, Bonnefond L, Matsumoto N, Nishizawa T, Nakanaga K, Aoki J et al. 2012 Structure and function of Zucchini endoribonuclease in piRNA biogenesis. Nature 491 284-287. (doi:10.1038/nature11509)

Olivieri D, Sykora MM, Sachidanandam R, Mechtler K \& Brennecke J 2010 An in vivo RNAi assay identifies major genetic and cellular requirements for primary piRNA biogenesis in Drosophila. EMBO Journal 29 3301-3317. (doi:10.1038/emboj.2010.212)

Pandey RR, Tokuzawa Y, Yang Z, Hayashi E, Ichisaka T, Kajita S, Asano Y, Kunieda T, Sachidanandam R, Chuma $\mathbf{S}$ et al. 2013 Tudor domain containing 12 (TDRD12) is essential for secondary PIWI interacting RNA biogenesis in mice. PNAS 110 16492-16497. (doi:10.1073/pnas. 1316316110)

Patil VS \& Kai T 2010 Repression of retroelements in Drosophila germline via piRNA pathway by the Tudor domain protein Tejas. Current Biology 20 724-730. (doi:10.1016/j.cub.2010.02.046)

Pek JW, Lim AK \& Kai T 2009 Drosophila maelstrom ensures proper germline stem cell lineage differentiation by repressing microRNA-7. Developmental Cell 17 417-424. (doi:10.1016/j.devcel.2009.07.017)

Pierik FH, Deddens JA, Burdorf A, de Muinck Keizer-Schrama SM, Jong FH \& Weber RF 2009 The hypothalamus-pituitary-testis axis in boys during the first six months of life: a comparison of cryptorchidism and hypospadias cases with controls. International Journal of Andrology 32 453-461. (doi:10.1111/j.1365-2605.2008.00877.x)

Pillai RS \& Chuma S 2012 piRNAs and their involvement in male germline development in mice. Development, Growth \& Differentiation 54 78-92. (doi:10.1111/j.1440-169X.2011.01320.x)

Rajasethupathy P, Antonov I, Sheridan R, Frey S, Sander C, Tuschl T \& Kandel ER 2012 A role for neuronal piRNAs in the epigenetic control of memory-related synaptic plasticity. Cell 149 693-707. (doi:10.1016/j. cell.2012.02.057)

Saito K, Ishizu H, Komai M, Kotani H, Kawamura Y, Nishida KM, Siomi H \& Siomi MC 2010 Roles for the Yb body components Armitage and Yb in primary piRNA biogenesis in Drosophila. Genes and Development 24 2493-2498. (doi:10.1101/gad.1989510) 
Sarkardeh H, Totonchi M, Asadpour O, Sadighi Gilani MA, Zamani Esteki M, Almadani N, Borjian Boroujeni P \& Gourabi H 2014 Association of MOV10L1 gene polymorphisms and male infertility in azoospermic men with complete maturation arrest. Journal of Assisted Reproduction and Genetics 31 865-871. (doi:10.1007/s10815-0140240-1)

Shoji M, Tanaka T, Hosokawa M, Reuter M, Stark A, Kato Y, Kondoh G, Okawa K, Chujo T, Suzuki T et al. 2009 The TDRD9-MIWI2 complex is essential for piRNA-mediated retrotransposon silencing in the mouse male germline. Developmental Cell 17 775-787. (doi:10.1016/j.devcel. 2009.10.012)

Soper SF, van der Heijden GW, Hardiman TC, Goodheart M, Martin SL, de Boer P \& Bortvin A 2008 Mouse maelstrom, a component of nuage, is essential for spermatogenesis and transposon repression in meiosis. Developmental Cell 15 285-297. (doi:10.1016/j.devcel.2008.05.015)

Tomari Y, Du T, Haley B, Schwarz DS, Bennett R, Cook HA, Koppetsch BS, Theurkauf WE \& Zamore PD 2004 RISC assembly defects in the Drosophila RNAi mutant armitage. Cell 116 831-841. (doi:10.1016/ S0092-8674(04)00218-1)

Ueyama T, Kasahara H, Ishiwata T, Yamasaki N \& Izumo S 2003 Csm, a cardiac-specific isoform of the RNA helicase Mov10l1, is regulated by Nkx2.5 in embryonic heart. Journal of Biological Chemistry 278 28750-28757. (doi:10.1074/jbc.M300014200)

Voronina E, Lovasco LA, Gyuris A, Baumgartner RA, Parlow AF \& Freiman RN 2007 Ovarian granulosa cell survival and proliferation requires the gonad-selective TFIID subunit TAF4b. Developmental Biology 303 715-726. (doi:10.1016/j.ydbio.2006.12.011)
Wang PJ, McCarrey JR, Yang F \& Page DC 2001 An abundance of X-linked genes expressed in spermatogonia. Nature Genetics 27 422-426. (doi:10.1038/86927)

Yadav RP \& Kotaja N 2014 Small RNAs in spermatogenesis. Molecular and Cellular Endocrinology 382 498-508. (doi:10.1016/j.mce.2013.04.015)

Yigit E, Batista PJ, Bei Y, Pang KM, Chen CC, Tolia NH, Joshua-Tor L, Mitani S, Simard MJ \& Mello CC 2006 Analysis of the C. elegans Argonaute family reveals that distinct Argonautes act sequentially during RNAi. Cell 127 747-757. (doi:10.1016/j.cell.2006.09.033)

Yoshida S 2010 Stem cells in mammalian spermatogenesis. Development, Growth \& Differentiation 52 311-317. (doi:10.1111/j.1440-169X.2010. 01174.x)

Zheng K \& Wang PJ 2012 Blockade of pachytene piRNA biogenesis reveals a novel requirement for maintaining post-meiotic germline genome integrity. PLoS Genetics 8 e1003038. (doi:10.1371/journal.pgen.1003038)

Zheng K, Xiol J, Reuter M, Eckardt S, Leu NA, McLaughlin KJ, Stark A, Sachidanandam R, Pillai RS \& Wang PJ 2010 Mouse MOV10L1 associates with Piwi proteins and is an essential component of the Piwi-interacting RNA (piRNA) pathway. PNAS 107 11841-11846. (doi:10.1073/pnas.1003953107)

Received 31 October 2014

First decision 1 December 2014

Revised manuscript received 4 February 2015

Accepted 9 February 2015 